Bangladesh J. Pl. Breed. Genet., 26(1): 35-40, 2013

\title{
GENETIC DIVERSITY IN VEGETABLE PEA (Pisum sativum L.)
}

\author{
M. Rahman, M. Hasan, R. N. Chowdhury, N. A. Ivy and M.M. Hossain ${ }^{1}$ \\ Department of Genetics and Plant Breeding \\ Bangabandhu Sheikh Mujibur Rahman Agricultural University \\ Gazipur 1706, Bangladesh
}

\begin{abstract}
An investigation was carried out to identify the extent of genetic divergence of seventeen vegetable pea genotypes at the Bangabandhu Sheikh Mujibur Rahman Agricultural University, Bangladesh. Genetic divergence was estimated using D 2 and principal component analysis. The genotypes under study fell into 4 clusters. The distribution pattern indicated that the maximum numbers of genotypes (6) were included in cluster II and cluster III and the minimum number in cluster IV (1). The inter-cluster distance was higher than the intracluster distance which indicated wider genetic diversity among the accessions of different groups. The highest inter-cluster distance was observed between II and IV. The lowest inter-cluster distance was observed between clusters II and III suggesting a close relationship among the genotypes of these two clusters. The highest intra-cluster distance was observed for the cluster II. The positive values of vector I and vector II for plant height, 50\% flowering and non-reducing sugar indicated that these characters had the highest contribution towards the divergence among the pea genotypes. The genotypes of vegetable pea from cluster II and cluster IV maybe selected as parents in future hybridization program.
\end{abstract}

Keywords: D $^{2}$ statistics, genetic divergence, PCA, vegetable pea

\section{INTRODUCTION}

Pea is an annual herbaceous plant of family Leguminosae and genus Pisum. Vegetable peas are cultivated for the fresh green seeds, tender green pods, dried seeds and foliage due to its high percentage of digestible protein along with carbohydrates, vitamins and minerals (Duke 1981).

At present the acreage and production of field pea in Bangladesh is very small. The production area has been drastically reduced due to introduction of HYV rice and wheat. In Bangladesh most of the pea varieties are inbred type and those are low yielder. Average yield of pea is very low (1 ton/ha) (BBS 2007). So, emphasis should be given to develop high yielding pea varieties. Genetic diversity has been considered as an important factor which is an essential prerequisite in the crop improvement program for obtaining high yielding progenies. Evaluation of genetic diversity is important to know the source of genes for a particular trait within the available germplasm. Moreover, genetic diversity among the segregating population helps select suitable types for

\footnotetext{
${ }^{1}$ Department of Horticulture, Bangabandhu Sheikh Mujibur Rahman Agricultural University, Gazipur 1706, Bangladesh
} 
commercial utilization (Pandey 2009). Therefore, the present investigation was designed to provide information on genetic divergence of 17 genotypes of vegetable pea.

\section{MATERIALS AND METHODS}

Seventeen genotypes of vegetable pea were studied to measure the diversity among the genotypes at the experimental farm and laboratories of Department of Genetics and Plant Breeding, Bangabandhu Sheikh Mujibur Rahman Agricultural University (BSMRAU), Gazipur in the year of 2008-09 (Table 1).

Table 1. List of 17 vegetable pea genotypes used as experimental materials

\begin{tabular}{cc}
\hline Genotype no. & Advanced lines \\
\hline G1 & L-002 \\
G2 & L-205 \\
G3 & LW X IPSA-3( L-120) \\
G4 & LW X IPSA-1 (L-227) \\
G5 & LW X IPSA-3 (L-121) \\
G6 & LW X IPSA-3 (L-25) \\
G7 & L-011 \\
G8 & EDP X IPSA-1( L-20) \\
G9 & EDP X IPSA-1 (L-117) \\
G10 & LW X IPSA-3 (L-105) \\
G11 & EDP X IPSA-1(L-219) \\
G12 & EDP X IPSA-1( L-135) \\
G13 & LW X IPSA-3 (L-187) \\
G14 & LW X IPSA-3 (L-26) \\
G15 & L-090 \\
G16 & EDP X IPSA-1( L-180) \\
G17 & EDP X IPSA-1 (L-17) \\
\hline
\end{tabular}

The field experiment was laid out in Randomized Complete Block Design (RCBD) with three replications. Data were recorded from randomly selected 10 plants from the plot of each replication on days to $50 \%$ flowering, plant height, pod no. per plant, pod length, seeds per pod, biological yield, dry seed yield, seed weight per plant, total seed weight, non-reducing sugar, reducing sugar and total sugar. Mean data for each character were subjected to multivariate analysis viz, principal component analysis (PCA), principal coordinate analysis (PCO), canonical variate analysis (CVA) and cluster analysis (CLSA) using GENSTAT 4.2b (Mahalanobis 1936; Jager, et al. 1983 and Digby, et al. 1989).

\section{RESULTS AND DISCUSSION}

Analysis of variance revealed significant differences among the genotypes for days to $50 \%$ flowering, plant height, pod no. per plant, pod length, seeds per pod, biological yield, dry seed yield, seed weight per plant, total seed weight, non-reducing sugar, reducing sugar and total sugar.

\section{Non-hierarchical clustering}

Non- hierarchical clustering using co-variance matrix grouped 17 pea genotypes into four different clusters. These results confirmed the clustering pattern of the genotypes obtained through principal component analysis. 
The pattern of distribution of genotypes into various clusters is given in Table 2 . The distribution pattern indicated that the maximum number of genotypes (6) were included in cluster II and III followed by I (4) and IV (1), respectively. Genetic diversity is generally associated with geographical diversity, but the former is not necessarily directly related with geographical distribution. The genotypes within the same clusters although formed specific clusters but were collected from different places, which indicated the geographical distribution and genetic divergence did not follow the same trend.

Table 2. Distribution of 17 vegetable pea genotypes in 4 clusters

\begin{tabular}{c|c|l}
\hline Cluster & $\begin{array}{c}\text { Number of } \\
\text { members }\end{array}$ & \multicolumn{1}{c}{ Genotypes } \\
\hline I & 4 & L-205, LW X IPSA-3 (L-26), L-011, LW X IPSA-3 (L-121) \\
II & 6 & $\begin{array}{l}\text { EDP X IPSA-1( L-20), EDP X IPSA-1 (L-117), EDP X IPSA-1 } \\
\text { (L-17), EDP X IPSA-1( L-135), EDP X IPSA-1( L-180), EDP X }\end{array}$ \\
& & $\begin{array}{l}\text { IPSA-1( L-20) } \\
\text { L-002, LW X IPSA-3( L-120), LW X IPSA-1 (L-227), LW X } \\
\text { III }\end{array}$ \\
& 6 & IPSA-3 (L-25), LW X IPSA-3 (L-105), L-090 \\
IV & 1 & LW X IPSA-3 (L-187)
\end{tabular}

\section{Canonical variate analysis}

Canonical variate analysis was performed to obtain the inter-cluster distances (Mahalnobis's $\mathrm{D}^{2}$ values). These values of inter-cluster distance $\left(\mathrm{D}^{2}\right)$ are presented in Table 3. Statistical distances represent the index of genetic diversity among the clusters. The inter-cluster distances were larger than the intra-cluster distances suggesting wider genetic diversity among the genotypes of different groups. Tiwari et al. (2004) and Sultana et. al. (2005) obtained larger inter-cluster distances than the intra- cluster distances in a multivariate analysis of pea.

The inter-cluster distance was maximum between cluster II and IV (26.562) followed by the distance between cluster III and IV (22.245) while the distance was minimum between cluster II and III (5.635). The maximum values of inter-cluster distance indicated that the genotypes belonging to cluster II were far diverged from those of cluster IV. These relations are also reflected in the scatter diagram (Fig. 1).

Table 3. Average Inter-cluster distance $\left(\mathrm{D}^{2}\right)$ and Intra-cluster distance (bold) for 17 vegetable pea genotypes

\begin{tabular}{c|c|c|c|c}
\hline & I & II & III & IV \\
\hline I & $\mathbf{1 . 3 4 7}$ & & & \\
II & 14.266 & $\mathbf{1 . 8 7 5}$ & & \\
III & 9.784 & 5.635 & $\mathbf{1 . 4 6 0}$ & \\
IV & 12.471 & 26.562 & 22.245 & $\mathbf{0 . 0 0 0}$ \\
\hline
\end{tabular}

\section{Construction of scatter diagram}

Based on the values of principal component scores 1 and 2 obtained from the principal component analysis, a two- dimensional scatter diagram $\left(Z_{1}-Z_{2}\right)$ using component score 1 as $\mathrm{X}$-axis and component score 2 as $\mathrm{Y}$ - axis was constructed, which is presented in Fig. 1 . The position of the genotypes in the scatter diagram was apparently distributed into four groups, which indicated that there exists considerable diversity among the genotypes. The scattered diagram for the pea genotype of four clusters revealed that the genotype viz. 13, 12, 8 and 7 were distantly located. 


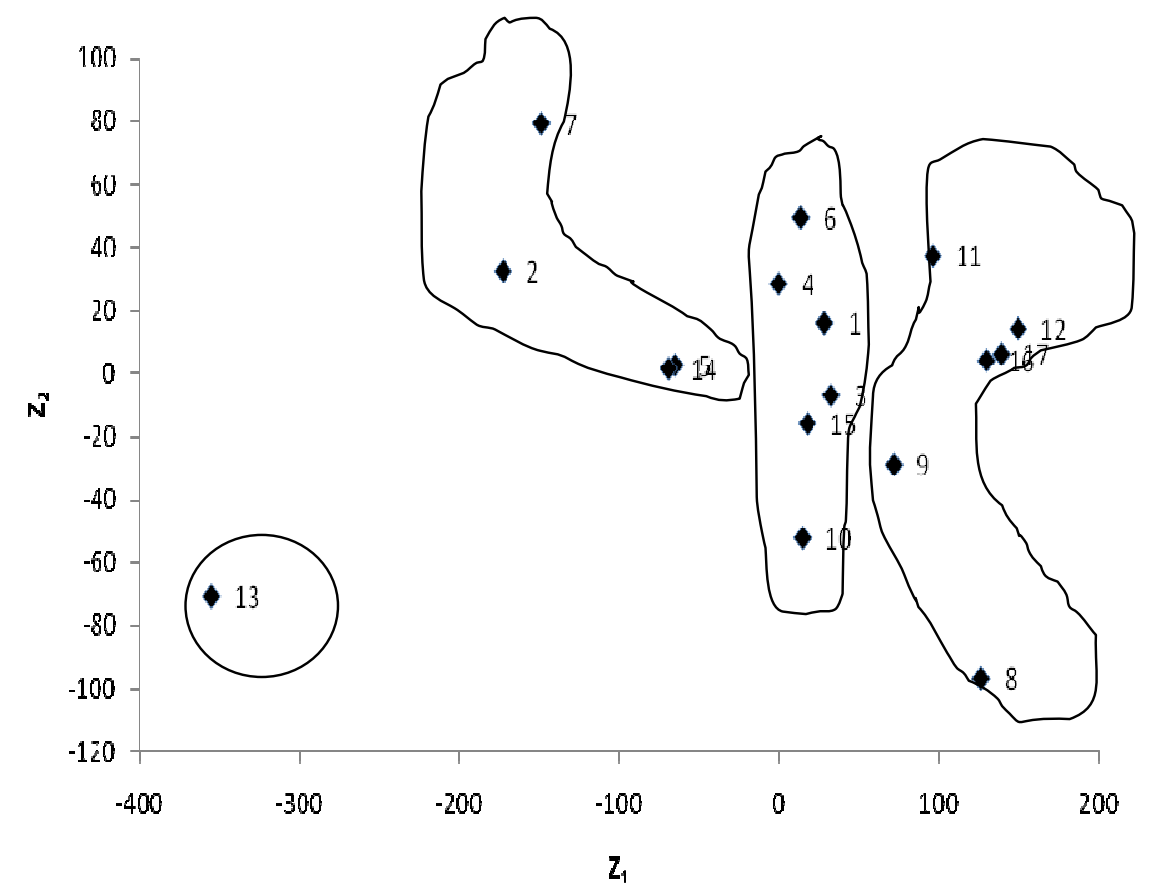

Fig. 1. Scatter distribution of 17 vegetable pea genotypes based on their principal component scores superimposed with clusters

\section{Intra-cluster mean}

Intra-cluster mean for 12 characters are presented in Table 4. It was observed that days to $50 \%$ flowering showed the highest intra cluster mean (58.33) in cluster IV followed by the cluster III (56.83), cluster II (54.28) and cluster I (49.83). Plant height showed the highest intra-cluster mean (109.07) in cluster IV. The lowest intra- cluster mean for this trait was observed in cluster II (49.17). Number of pods per plant had the highest group mean in cluster IV (20.27). The lowest intra- cluster mean for this trait was observed in cluster II (11.05). Pod length $(\mathrm{cm})$ ) showed the highest intra- cluster mean (5.11) in cluster I. The lowest intra- cluster mean for this trait was observed in cluster III (4.15). Seeds per pod had the highest intra- cluster mean (4.51) in cluster I. The lowest intra- cluster mean for this trait was observed in cluster III (3.85). Primary biological yield ( $\mathrm{kg} / \mathrm{ha})$ showed the highest intracluster mean (606.67) in cluster IV. The lowest intra- cluster mean for this trait was observed in cluster II (170.06). Dry seed yield ( $\mathrm{kg} / \mathrm{ha}$ ) had the highest intra- cluster mean (161.43) in cluster IV. The lowest intra- cluster mean for this trait was observed in cluster II (35.04). Seed weight per plant (gm) showed the highest intra- cluster mean (28.61) in cluster IV. The lowest intra- cluster mean for this trait was observed in cluster II (9.98). Total seed weight $(\mathrm{kg} / \mathrm{ha})$ showed the highest intra- cluster mean (166.17) in cluster IV. The lowest intracluster mean for this trait was observed in cluster II (37.66). Non-reducing sugar (mg/100g) had the highest intra- cluster mean (9.26) in cluster IV. The lowest intra- cluster mean for this trait was observed in cluster II (7.21). Reducing sugar (mg/100g) showed the highest intracluster mean (4.28) in cluster I. The lowest intra- cluster mean for this trait was observed in cluster IV (2.02). Total sugar (mg/100g) showed the highest intra- cluster mean (11.98) in cluster I followed by the cluster IV (11.23) while the lowest intra- cluster mean for this trait was observed in cluster II (10.5). 
Table 4. Cluster mean for 12 characters of vegetable pea genotypes

\begin{tabular}{l|r|r|r|r}
\hline \multirow{2}{*}{\multicolumn{1}{c}{ Characters }} & \multicolumn{4}{c}{ Clusters } \\
\cline { 2 - 5 } & \multicolumn{1}{c}{ I } & \multicolumn{1}{c}{ II } & \multicolumn{1}{c}{ III } & \multicolumn{1}{c}{ IV } \\
\hline 1.Days to 50\% flowering & 49.83 & 54.28 & 56.83 & 58.33 \\
2.Plant height (cm) & 53.98 & 49.17 & 62.68 & 109.07 \\
3.Pod No. per plant & 16.66 & 11.05 & 14.44 & 20.27 \\
4. Pod length (cm) & 5.11 & 5.01 & 4.15 & 4.5 \\
5.Seeds per pod & 4.51 & 3.98 & 3.85 & 4.27 \\
6.Biological yield (kg/ha) & 404 & 170.06 & 270.78 & 606.67 \\
7.Dry seed yield (kg/ha) & 54.16 & 35.04 & 40.43 & 161.43 \\
8.Seed weight per plant (gm) & 12.61 & 9.98 & 11.3 & 28.61 \\
9.Total seed weight (kg/ha) & 56.82 & 37.66 & 48.37 & 166.17 \\
10.Non reducing sugar (mg/100g) & 7.66 & 7.21 & 7.97 & 9.26 \\
11.Reducing sugar (mg/100g) & 4.28 & 2.83 & 3.78 & 2.02 \\
12.Total sugar (mg/100g) & 11.98 & 10.5 & 11.18 & 11.23 \\
\hline
\end{tabular}

\section{Contribution of characters towards diversity}

The characters contributing maximum to the divergence are given greater emphasis for deciding on the cluster for the purpose of further selection and the choice of parents for hybridization (Akther 2013, Siddique 2010).

Contribution of characters towards divergence obtained from CVA is presented in Table 5. The values of vector I and vector II revealed that both the vectors had positive values for Days to 50\% flowering and Plant height $(\mathrm{cm})$. These results indicated that these characters had the highest contribution towards the divergence among the 17 pea genotypes. In vector I other important characters responsible for the genetic divergence in the major axis of differentiation were seeds per pod, seed weight per plant (gm), non reducing sugar $(\mathrm{mg} / 100 \mathrm{~g})$, reducing sugar $(\mathrm{mg} / 100 \mathrm{~g})$ having positive vector values.

While in vector II (the second axis of differentiation), pod length $(\mathrm{cm})$, dry seed yield $(\mathrm{kg} / \mathrm{ha})$, total sugar $(\mathrm{mg} / 100 \mathrm{~g})$ were important. Negative values in both vectors for pod no. per plant, biological yield ( $\mathrm{kg} / \mathrm{ha})$, Total seed weight $(\mathrm{kg} / \mathrm{ha})$ had the lowest contribution to the divergence.

From the above results it appeared that contribution of plant height $(\mathrm{cm})$ was the highest followed by days to $50 \%$ flowering and non-reducing sugar $(\mathrm{mg} / 100 \mathrm{~g})$ to the total divergence in pea genotypes.

Table 5. Latent vector for 12 characters of 17 vegetable pea genotypes

\begin{tabular}{lcc}
\hline Principal component axis & Vector I & Vector II \\
\hline Days to 50\% flowering & 0.0131 & 0.092 \\
Plant height $(\mathrm{cm})$ & 0.0417 & 0.0291 \\
Pod no. per plant & -0.2179 & -0.0337 \\
Pod length $(\mathrm{cm})$ & -0.3912 & 1.0501 \\
Seeds per pod & 0.1256 & -1.0234 \\
Biological yield $(\mathrm{kg} / \mathrm{ha})$ & -0.0535 & -0.0046 \\
Dry seed yield $(\mathrm{kg} / \mathrm{ha})$ & -0.0011 & 0.1005 \\
Seed weight per plant $(\mathrm{gm})$ & 0.6026 & -0.0291 \\
Total seed weight $(\mathrm{kg} / \mathrm{ha})$ & -0.1291 & -0.0448 \\
Non reducing sugar $(\mathrm{mg} / 100 \mathrm{~g})$ & 1.4993 & -1.0736 \\
Reducing sugar $(\mathrm{mg} / 100 \mathrm{~g})$ & 0.8924 & -1.0066 \\
Total sugar $(\mathrm{mg} / 100 \mathrm{~g})$ & -1.1458 & 0.6714 \\
\hline
\end{tabular}

Genetic diversity was studied to detect the more diverse pea genotypes which might be used in hybridization program. Seventeen genotypes were grouped into four different clusters and the maximum number of genotypes (6) were included in cluster II and cluster III. The highest inter-cluster distance was observed between II and IV while the highest intracluster distance was observed for cluster II. Considerable divergence for all the characters 
among the genotypes was observed. Considering the obtained results, genotypes of vegetable pea from cluster II and cluster IV maybe selected as parents in future hybridization program.

\section{REFERENCES}

Akther, C. A., M. Hasan, M. S. Raihan, M. M. Hossain and M. A. K. Mian. 2013. Genetic Divergence in Stem Amaranth (Amaranthus tricolor L.) Genotypes for Yield and its Component Characters. The Agriculturists. 11(1): $82-88$.

BBS, 2007. Bangladesh Bureau of Statistics, p. 65.

Digby, P., M. Galwy and P. Lane. 1989. Genstat. A second course. Oxford Science publications, Oxford. 103-108pp.

Duke, J. A. 1981. Hand book of legumes of world economic importance. Plenum Press, New York. 199-265 pp.

Jager, M. I., D. Gerethojones and E. Griffiths. 1983. Components of partial resistance of wheat seedlings to Steptoria nodurum. Euphytica. 32: 575-585.

Mahalanobis, P. C. 1936. On the generalized distance in statistics. Proeedings of National Institute of Science. 2: 49-55 .

Pandey, R. M. 2009. Genetic divergence of parents and $F_{2}$ segregation in grain Amaranths. Ciencia e investigación agrarian. 36(1): 77-84.

Siddique, M. A., E. S. Rashid, M. H. Khalequzzaman; M. Z. Islam and M. H. K. Baktiar. 2010. Genetic diversity of local rainfed rice (Oryza Sativa L.). Bangladesh J. Pl. Breed. Genet. 23(2): 41-46.

Sultana, Z., A. K. M. A. Islam; M. G. Rasul, N. Sultana and M. A. K. Mian. 2005. Genetic diversity in vegetable pea (Pisum sativum). Bangladesh J. Pl. Breed. Genet. 18(1): 07-12.

Tiwari, S. K., R. Kumar, H. L. Singh and R. P. Katiyar. 2004. Genetic diversity analysis in pea (Pisum sativum L.). Indian J. Agric. Res. 38(1): 60- 64. 